\title{
Electron-driven engineering of graphene - RETRACTION
}

Mark H. Rümmeli, Alicja Bachmatiuk, Young Hee Lee, and Juergen Eckert

doi: 10.1557/jmr.2013.279, Published by Materials Research Society with Cambridge University Press, 15 October 2013.

This article has been retracted at the request of the authors.

Figures 3 and 4 were reproduced from the $\mathrm{PhD}$ thesis of Dr Felix Börrnert without explicit request, permission or acknowledgement. This was an oversight by the corresponding author, Dr Rümmeli. The rest of the paper is unaffected and the results stand as presented.

\section{REFERENCE}

1. M.H. Rümmeli, A. Bachmatiuk, Y.H. Lee, and J. Eckert: Electron-driven engineering of graphene. J. Mater. Res. Published by Cambridge University Press, 15 October 2013. doi: http://dx. doi.org/10.1557/jmr.2013.279. 